\section{Concepções populares de normalidade e saúde mental no litoral norte da Bahia, Brasil}

\author{
Mental health and normality: popular conceptions \\ in a northern coastal area of Bahia, Brazil
}

Abstract

1 Universidade de Salvador, Salvador, Brasil.

2 Instituto de Saúde Coletiva, Universidade Federal da Bahia, Salvador, Brasil.

Correspondência M. T. A. D. Coelho Universidade de Salvador. Rua Theodomiro Baptista 150, apto. 102, Salvador, BA 41940-320, Brasil. therezacoelho@pop.com.br
This study focuses on signs, meanings, and practices related to mental normality and health in a northern coastal area of Bahia, Brazil. It discusses local conceptions about the non-existence or exclusive existence of mental normality, as well as points of view concerning total mental normality. It identifies the prototypes of normality, like "normal", "almost normal", and "false normal", as signs for distinguishing mentally normal persons. The article discusses the underlying values and concepts in local personal classification of mental normality and proposes a structural health device consisting of moral, scientific, religious, environmental, and social elements. It analyzes local normalization and mental health promotion actions and the local system of signs, meanings, and practices of normality. Finally, the article analyzes the primary, secondary, and tertiary levels of health. All these goals are met by comparing local conceptions with the scientific literature on medical epistemology, psychoanalysis, sociological labeling theory, and medical anthropology.

Epistemology; Psychoanalysis; Sociology; Anthropology
Maria Thereza Ávila Dantas Coelho ${ }^{1}$ Naomar de Almeida Filho 2

\section{Introdução}

Desde 1970, quando os principais sistemas de saúde entraram em crise devido, sobretudo, a uma excessiva concentração na dimensão curativa da doença, vem sendo apontada a necessidade de estudar-se o tema da normalidade e saúde, considerando sua vertente positiva. Ressurgiu a discussão sobre o papel do estilo de vida e das condições ambientais e de vida no processo saúde/doença, e ganhou força a idéia de promoção da saúde, emergindo os conceitos de vigilância da saúde, políticas públicas saudáveis e cidades saudáveis. Apesar do aparecimento de novos modelos assistenciais e de propostas de intervenções intersetoriais que promovam a saúde, poucas pesquisas têm seguido, entretanto, nessa direção 1,2,3,4,5,6,7,8,9, $10,11,12,13,14,15$. A maior parte das investigações tem se dedicado, sobretudo, às questões ligadas à enfermidade ou ao sofrimento. Permanece uma grande carência de estudos empíricos que revelem como os membros de um dado grupo social identificam indivíduos mentalmente normais, que significados dão aos seus atributos e quais atividades práticas consideram relacionadas à normalidade mental. O conhecimento desses aspectos é essencial para o planejamento de ações de saúde mental nas comunidades.

Dentro desse contexto, realizamos uma pesquisa para explorar os signos, significados e prá- 
ticas relacionados à normalidade e saúde mental, por membros de um grupo social. Adotamos o referencial da teoria dos sistemas de signos, significados e práticas, na perspectiva de que os signos se referem aos comportamentos que apontam para a normalidade e a saúde, os significados dizem respeito às idéias apresentadas sobre os mesmos, e as práticas compreendem as reações das pessoas frente aos indivíduos considerados normais ou anormais 16,17. Buscamos apreender os diversos elementos semióticos, simbólicos e pragmáticos ligados à normalidade e saúde mental, em suas variações subculturais e individuais. Ainda que as múltiplas concepções particulares ao grupo pesquisado tenham sido aproximadas das importantes contribuições teóricas ao estudo desse tema, foi, sobretudo, enquanto categoria cultural e subjetiva que a normalidade e saúde mental foram aqui abordadas.

\section{Metodologia}

A pesquisa foi feita em uma área do litoral norte da Bahia, que dista aproximadamente $150 \mathrm{~km}$ da sua capital e possui uma população de 20.426 habitantes, sendo 10.210 homens e $10.216 \mathrm{mu}$ lheres (Instituto Brasileiro de Geografia e Estatística. Censo 2000. http://www.ibge.com.br, acessado em 18/Mar/2005). O local apresenta relevantes heterogeneidades demográficas, econômicas, sociais, culturais e religiosas. Pessoas de classe média em ascensão, proprietárias de terras ou de pequenos negócios convivem com pessoas de classe mais baixa, que se dedicam à agricultura, pecuária, produção de coco, leite e derivados, pesca, turismo, artesanato e serviços urbanos 18 . Devido aos movimentos migratórios e ao turismo, ao longo dos anos, novos costumes se somaram aos antigos, incrementando a pluralidade das idéias, valores e condutas dos habitantes, que praticam, de forma ortodoxa ou sincrética, as religiões católica, espírita, pentecostais ou afro-brasileiras. Tal diversidade possibilitou a apreensão de variadas concepções populares sobre normalidade e saúde mental.

Utilizamos o referencial metodológico de uma pesquisa, que se encontrava em andamento na mesma área, intitulada Social and Cultural Landmarks in Community Mental Health Phase 1 Signs, Meanings and Practices Related to Mental Health in Bahia, Brazil (INECOM. The International Network for Cultural Epide- miology and Comunity Mental Health. Montreal: WHO Collaborating Centre for Research and Training in Mental Health; 1993). Esse referencial propõe que sejam estudadas pessoas do centro e da margem da sociedade, de modo a apreender as múltiplas vozes e pontos de vista a partir dos quais as pessoas constroem suas interpretações. Como a investigação em curso encontrou, além de referências a problemas mentais, signos de normalidade e reações de normalização, utilizamos parte dos dados já coletados anteriormente. Tal coleta se deu em três etapas, mediante o consentimento das pessoas: pré-enquete, enquete extensiva e reconstrução de casos 19. A pré-enquete consistiu de entrevistas abertas, gravadas em áudio, com 15 informantes-chave, e tinha o objetivo de identificar termos e comportamentos relacionados com problemas mentais. A enquete extensiva compreendeu entrevistas fechadas e não gravadas com 120 informantes ( 57 homens e 63 mulheres) e objetivou identificar os casos cujos comportamentos eram considerados problemáticos, assim como os potenciais informantes-chave dos mesmos. A etapa da reconstrução de casos abrangeu entrevistas abertas, semi-estruturadas e gravadas, com 22 homens e 38 mulheres, e visou coletar narrativas dos protótipos de problema mental.

Uma vez que os signos de normalidade e as reações de normalização advieram a partir da reconstrução da história de problemas mentais, tornou-se necessário explorar o tema da normalidade de uma forma mais ampla. Fomos, então, ao campo para uma coleta complementar de dados, específica para este estudo. Inicialmente, os contatos com os moradores foram realizados por intermédio de alguns investigadores que já conheciam a área. Posteriormente, fizemos os próprios contatos, muitos dos quais ocorridos espontaneamente. Realizamos, assim, 33 entrevistas semi-estruturadas no local, com 15 pessoas do sexo feminino e 18 do sexo masculino, que também apresentavam características heterogêneas quanto à idade, escolaridade, estado civil, religião, classe e situação laboral. Dentre essas 33 pessoas entrevistadas, apenas algumas eram informantes-chave da outra pesquisa em andamento. As demais foram escolhidas aleatoriamente e possuíam diferentes ocupações. Enquanto algumas ainda estudavam, outras trabalhavam em fábrica, órgão público, associação cultural e esportiva, matadouro, residência, rádio, restaurante e farmácia. Havia também indivíduos de- 
sempregados, que viviam da ajuda de seus familiares. A opção por entrevistar novas pessoas se deveu ao objetivo de abordar a normalidade e saúde mental sem vinculá-las necessariamente a um problema mental, o que poderia induzir a concepção da normalidade enquanto ausência de doença.

As entrevistas complementares foram feitas com o consentimento das pessoas, nos mais diversos locais e horários, tanto em situações de trabalho, quanto de descanso ou divertimento: casas, ruas, sítios, barracas de praia, restaurantes, fábricas, matadouro e feira. Elas foram gravadas em áudio e, posteriormente, transcritas e armazenadas em microcomputador. Usamos expressões lingüísticas locais para facilitar a compreensão e a emergência das próprias concepções nativas. Nesses momentos, alguns dos signos e das ações relacionadas pelos informantes à normalidade mental puderam ser diretamente observados. Tais entrevistas exploraram os significados dos termos de referência à normalidade mental e identificaram aspectos não focalizados anteriormente, como práticas de promoção da saúde, concepções sobre a normalidade mental total, coexistência de momentos normais e anormais num mesmo indivíduo e normalidade posterior à enfermidade mental.

As 60 reconstruções de caso e as 33 entrevistas complementares foram analisadas com base na teoria dos sistemas de signos, significados e práticas 16,17,20,21,22,23,24. Essa teoria propõe uma perspectiva êmica de investigação, aberta a comparações e generalizações no nível do conhecimento científico. Além da influência dos fatores macrossociais e culturais, ela enfatiza a autonomia dos indivíduos na transformação dos fatos sociais de modo que, ao lado dos significados coletivamente compartilhados, marca a importância de considerar-se os significados singulares de cada sujeito.

No processo de análise, realizamos tanto leituras internas a cada narrativa, quanto leituras que aproximavam diferentes narrativas em função de um dado aspecto investigado. Após várias leituras, agrupamos os fragmentos de discurso afins em diferentes categorias: (1) normalidade mental inexistente; (2) normalidade mental exclusiva; (3) normalidade mental total; (4) relacionamento interpessoal; (5) trabalho; (6) divertimento; (7) cuidado de si e dos objetos; e (8) vida psíquica. Uma vez feito tal agrupamento, identificamos e descrevemos os protótipos de normalidade mental e analisamos os fundamentos lógicos e epistemológicos desta classificação. Passamos, então, à investigação dos fatores de transição entre a normali- dade e a anormalidade mental, bem como dos elementos determinantes da normalidade. Buscamos apreender, em seguida, as ações locais de normalização e promoção da saúde, e a percepção da sua eficácia terapêutica. Por fim, analisamos as distintas concepções, ações e dimensões da normalidade mental.

A análise das entrevistas se deu em dois níveis 17 . No primeiro, revelamos os signos, significados e práticas de normalidade mental tais como eles foram explicitados pelos entrevistados. No segundo nível, estabelecemos relações entre as concepções populares e o quadro científico da pesquisa. Essas relações se referiram à associação das idéias e ações com o seu contexto coletivo e individual, com o conceito de normalidade mental e à relação interna entre os seus signos, significados e práticas. Em ambos os níveis de interpretação, a polissemia e a intertextualidade constituíram referenciais importantes.

\section{Protótipos populares de normalidade mental}

Constatamos múltiplos pontos de vista locais sobre a normalidade mental, inclusive as posições extremas e opostas que concluem pela sua inexistência ou existência exclusiva: "neste mundo, não existe ninguém normal, porque todo o mundo é desorientado". "Todo mundo é normal, todo mundo tem a cabeça boa".

A maior parte dos entrevistados, entretanto, afirmou a existência tanto da normalidade quanto da anormalidade mental. De acordo com o informante acima, que negou a existência da normalidade, com a deterioração das condições de vida da população, todos ficaram "desorientados" e a normalidade desapareceu. Tal concepção se aproxima do dispositivo patogênico estrutural de Bibeau \& Corin 19, na medida em que atrela o adoecimento da população aos seus elementos macrossociais 17. Ela leva, entretanto, esse pensamento às suas últimas conseqüências, quando afirma que a normalidade deixou de existir porque todos os indivíduos adoeceram em função da precária condição de vida da população.

Verificamos também que, enquanto alguns informantes admitiram a normalidade mental total, outros a negaram: "então às vezes tem atitudes anormais numa pessoa, mas se uma pessoa é totalmente normal ela não deveria ter atitude anormal, não é verdade? Então não existe ninguém totalmente normal". Os entrevistados que defenderam a existência da normalidade mental total, entretanto, não apresentaram ca- 
racterísticas concretas que distinguissem as pessoas totalmente normais das normais: "tem o normal e o totalmente normal. O totalmente normal deve ser melhor de o que o normal, né? Agora explicar ...". Isso aponta para a possibilidade da normalidade total ser, para eles, mais um ideal do que uma realidade vivenciada. Tal perspectiva se coaduna com o ponto de vista da psicanálise na medida em que, para esta, um eu totalmente normal é uma ficção 25 . Ela se aproxima também do critério de normalidade ideal encontrado na psicopatologia, segundo o qual é normal o que é supostamente mais evoluído e sadio 26.

Ao mesmo tempo em que indivíduos portadores de características socialmente desejadas foram percebidos como normais pelos entrevistados, pessoas desprovidas dessas características foram consideradas como anormais.

“(...) O que é normal? É uma coisa mais comum (...) normal são pessoas que têm trabalho, família e estão neste padrão de vida do mundo. (...) As pessoas normais são isso, elas desenvolvem atividades do cotidiano, da mesma forma que a maioria faz".

Tal perspectiva coincide com a relação apontada por Goffman 27 entre normalidade mental e posse de atributos esperados pela sociedade. Os estudos de Pondé 28, Lima 29 e Peres 30, realizados na mesma região, apontam para esse resultado. Entretanto, a categorização local das pessoas não se deu de uma forma simples, pois, diferentemente da idéia veiculada pela teoria do rótulo 27, elas não foram vistas apenas como normais ou anormais. Pessoas quase-normais e falso-normais perpassaram o universo imaginário de alguns nativos, tornando mais complexa a sua classificação: "ele obedece, ele tem o maior medo e o maior respeito pela mãe dele; quando ele tá (...) quase-normal". De acordo com um informante, por exemplo, existem pessoas que se mostram normais, mas que, entretanto, não o são. Ele se referiu às mesmas com o termo "psicopata”. Afirmou que elas se revelam dóceis quando, na realidade, são agressivas e maldosas. Agem como se fossem amigas, quando são inimigas.

Tais categorias se aproximam dos protótipos de Young 31 e Lakoff 32 , na medida em que a sua identificação foi realizada por um pequeno número de indivíduos, baseada num raciocínio analógico instável. As pessoas quase-normais e falso-normais se assemelham, em parte, aos indivíduos considerados normais e, em outros aspectos, se parecem com os sujeitos tidos como anormais. Por tal razão, tais categorias apresentam gradações e limites nebulosos em relação à normalidade e à anormalidade men- tal. Isso revela a existência de uma continuidade entre esses dois extremos, uma vez que eles não são vistos como mutuamente excludentes. Com relação especificamente ao protótipo de falsa-normalidade, esse se mostrou relativo ao referencial do avaliador, na medida em que algumas pessoas podem considerar-se normais e, ao mesmo tempo, ser percebidas como anormais pelos demais. Assim, os signos de normalidade podem variar a depender do contexto de cada indivíduo.

“De repente, você é pirada e o normal para você é quem é pirado (...) quando você define alguma coisa você define de acordo com seu referencial. Então este referencial é o normal".

Os protótipos de pessoa normal, quase-normal e falso-normal constituem, portanto, tipos humanos próprios à comunidade estudada, que se aproximam, em certos aspectos, do pensamento de Freud 25, Canguilhem 33 e Gadamer 34 . Freud 25 afirmava, por exemplo, que todo indivíduo se aproxima do neurótico e do psicótico, num lugar ou noutro. Canguilhem 33 , por sua vez, defendia que a patologia instaura uma nova norma de vida. Gadamer ${ }^{34}$, por fim, postulava que a diferença entre a saúde e a enfermidade não pode ser claramente definida.

Além da nebulosidade dos limites entre as categorias e da relatividade, alguns conceitos e valores também basearam a classificação local das pessoas quanto à normalidade e anormalidade mental, conforme a Figura 1.

Dentre os pares conceituais fundamentais, encontramos positividade e negatividade, presença e ausência, correção e erro, bondade e maldade, quantidade e qualidade, comum e incomum, essência e aparência, capacidade e incapacidade, semelhança e diferença. A positividade e a negatividade apareceram sob duas formas distintas, ora como qualidade, ora como característica gramatical. Enquanto qualidade, elas foram explicitamente associadas à atividade do pensamento, na medida em que se considerou que a pessoa normal pensa positivamente, ao contrário da pessoa anormal. Como característica gramatical, elas apontaram para a afirmação ou negação de determinados atributos ou atitudes, uma vez que as pessoas normais fazem certas coisas e deixam de realizar outras, como, por exemplo, trabalhar e não expor a vida das pessoas ao perigo.

Os conceitos presença e ausência, correção e erro, bondade e maldade, comum e incomum, capacidade e incapacidade estão relacionados entre si, uma vez que a presença de atitudes corretas, boas, comuns e que demonstram capacidade apontam para a normalidade, ao tem- 

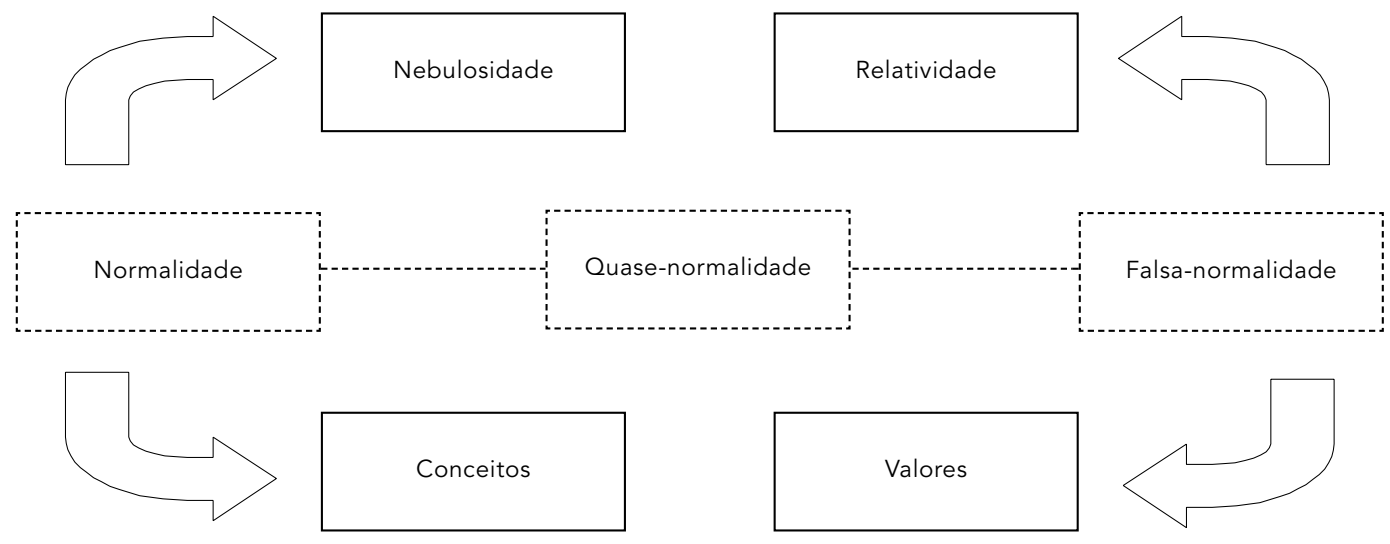

po em que a sua ausência indica uma anormalidade. Especificamente com relação à associação entre o bem e a normalidade, esta se aproxima da idéia defendida por Good 35 , segundo a qual a fronteira entre o normal e o patológico é estabelecida pela cultura, imbuída pela perspectiva moral da concepção de bom. Quanto aos conceitos quantidade e qualidade, estes fundamentam o significado de vários signos, como, por exemplo, ingerir bebida alcoólica e dançar. Ou seja, o consumo de álcool precisa ocorrer dentro de certo limite e a dança obedecer a determinado padrão para que ambos sejam considerados indicativos de normalidade mental.

Com relação aos conceitos essência e aparência, verificamos que uma pessoa pode ser considerada aparentemente normal e essencialmente anormal, e vice-versa, o que cria um ponto de incerteza na classificação das pessoas. Nessa perspectiva, o saber sobre a normalidade é sempre aparente, parcial e provisório, pois não há como conhecer alguém totalmente, de modo que um indivíduo pode mostrar-se normal num contexto e, noutro, revelar uma anormalidade.

Quanto aos conceitos semelhança e diferença, vimos que as pessoas que se consideram mentalmente normais identificam os indivíduos igualmente normais pelo critério da semelhança a si mesmo. A título de exemplo, referindo-se a uma conterrânea, uma entrevistada afirmou que “(...) se ela fosse normal, era como eu”. Tal concepção se coaduna com o pensamento de Foucault 36, quando este afirma que as pessoas não se reconhecem no indivíduo doente que elas rejeitam.

Através dos protótipos de pessoa normal, quase-normal e falso-normal, constatamos que os signos locais de normalidade mental revelam princípios normativos. Ou seja, os entrevistados estabeleceram uma série de características para a normalidade mental baseadas, justamente, em seus valores. A razão etimológica da relação entre as noções de saúde e valor já foi apontada por Canguilhem 37: valor origina-se da palavra latina valere, que significa portar-se bem, passar bem de saúde. Assim, os valores revelados pelas concepções e práticas locais de saúde orientam as idéias e as ações dos indivíduos, configurando o que Good 35 e Good \& Good 38 definiram como rede semântica. A Figura 2 apresenta alguns dos valores locais associados pelos entrevistados à normalidade mental.

A relação entre a rede semântica da normalidade mental e a vida global dos entrevistados reflete a própria origem etimológica da palavra saúde, que remete ao radical grego antigo hólos, cujo significado é todo 39 . Nesse sentido, falar sobre a saúde é falar sobre a vida como um todo. Quando os informantes revelaram os signos, significados e práticas relacionados à normalidade mental, expressaram também o seu modo de vida e os seus fundamentos. 
Rede semântica da normalidade mental.

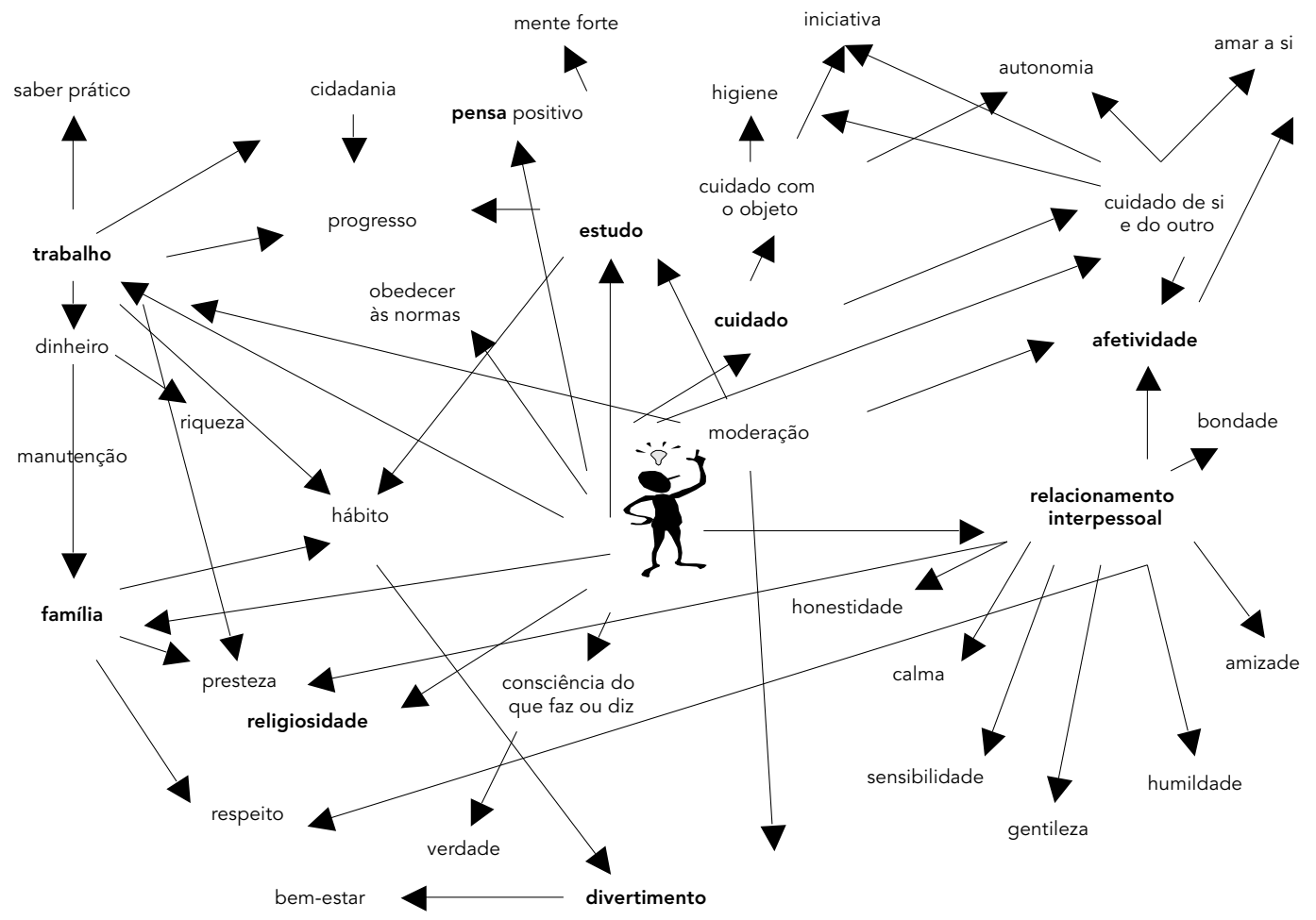

\section{Práticas populares de normalidade e saúde mental}

Verificamos a existência, na área, de diferentes práticas de normalização e promoção de saúde mental. Tal diversidade é um sinal de que a sociedade percebe os limites da medicina oficial e busca atuar nos diversos níveis da doença. Esse aspecto já vem sendo discutido por alguns autores no campo científico 40,41,42. Enquanto as práticas biomédicas se dirigem ao corpo biológico e interpretam o sofrimento humano em termos de disfunções fisiológicas, as demais ações se voltam para aspectos psíquicos, culturais e espirituais e dão outros significados aos estados de saúde-doença. Ou seja, os indivíduos interpretam o sofrimento humano de diferentes formas. Os cuidados caseiros, por exemplo, quer envolvam a administração de substâncias ou não, como chás e aromas, implicam um acolhimento familiar e uma doação de afeto, que não estão presentes nas consultas médicas. É muito diferente a forma como as folhas são utilizadas na confecção de chás e nos trabalhos realizados pelas rezadeiras, pais ou mães-de-santo. Nesses casos, acredita-se estar em jogo dimensões espirituais e mágicas, que transcendem os efeitos meramente afetivos e físico-químicos da administração das folhas.

Nem sempre as ações de normalização foram consideradas eficazes pelos informantes. Em alguns casos, os entrevistados atribuíram o insucesso do tratamento à não-correspondência entre a suposta causa do problema e a terapêutica aplicada. Fazendo uma analogia com o modelo biomédico, é como se tivesse ocorrido um erro de diagnóstico e o remédio não funcionasse, porque servisse para outro transtorno e não para aquele.

$$
\begin{aligned}
& \text { “- E o que ela fazia pra ele?” } \\
& \text { “- Era negócio de banho mesmo.” } \\
& \text { “- Banho de quê?” }
\end{aligned}
$$

“- Banho dessas folhas, era Guiné, era Pitimbóia, era Pinhão Roxo, era um mato que chamava Erva Ciente (...). Pra tirar os olhos maus; os olhos ruim que botam em cima de uma pessoa (...) Mas ele não melhorou, porque o sofrimento dele não era disso não (...)." 
“- É? Por quê?”

“- (...) Era de coisa de macumba, viu? Só podia ficar bom com esses negócios do lado da macumba."

Tal explicação remete ao pensamento de Kleinman 40,41,43, segundo o qual os diversos atores sociais apresentam diferentes explicações para as enfermidades, que necessitam ser negociadas no processo de cura. Ela se aproxima ainda da teoria dos sistemas de signos, significados e práticas quando esta afirma que certos signos adquirem, culturalmente, determinados significados a que correspondem reações sociais particulares, configurando um sistema 16. A correspondência entre as ações de promoção de saúde e os signos e significados de normalidade mental aponta para um sistema de signos, significados e práticas também no nível da promoção de saúde mental. A título de exemplo, atitudes como trabalhar, estudar e não consumir bebida alcoólica, ou consumi-la moderadamente, tanto identificam as pessoas mentalmente normais, quanto produzem e mantêm a normalidade.

Outras ações ligadas à normalidade mental foram concebidas pelos entrevistados como sendo da responsabilidade do Estado, como colocar o enfermo na cadeia durante uma cri- se, tratá-lo numa "fazenda terapêutica”, promover uma educação para a saúde ou resolver os problemas da fome e da baixa renda. Essas ações apontam para a importância não só da dimensão curativa, mas também da prevenção, promoção e transetorialidade nas ações de saúde. De acordo com os informantes, a saúde mental não é apenas uma questão que diz respeito aos médicos e aos hospitais, mas também à polícia e aos órgãos ligados à economia. Nesse sentido, a normalidade está vinculada tanto ao setor saúde quanto aos setores da segurança, justiça, infra-estrutura e trabalho. As novas propostas de política de saúde apontam, justamente, para a importância dessa transetorialidade 44,45,46,47,48,49,50.

Verificamos, assim, que múltiplos foram os fatores associados pelos entrevistados à normalidade e à saúde mental. Podemos fazer uma analogia com o dispositivo patogênico estrutural de Bibeau 17 e Bibeau \& Corin 19 e considerar que a ciência, a religião, a moral, o ambiente e a situação sócio-econômica integram um dispositivo estrutural de saúde, ligado tanto aos determinantes da normalidade, quanto às ações de normalização e promoção da saúde (Figura 3).

Verificamos também que, enquanto algumas idéias dos entrevistados revelaram-se pró-

Figura 3

Dispositivo estrutural de saúde.
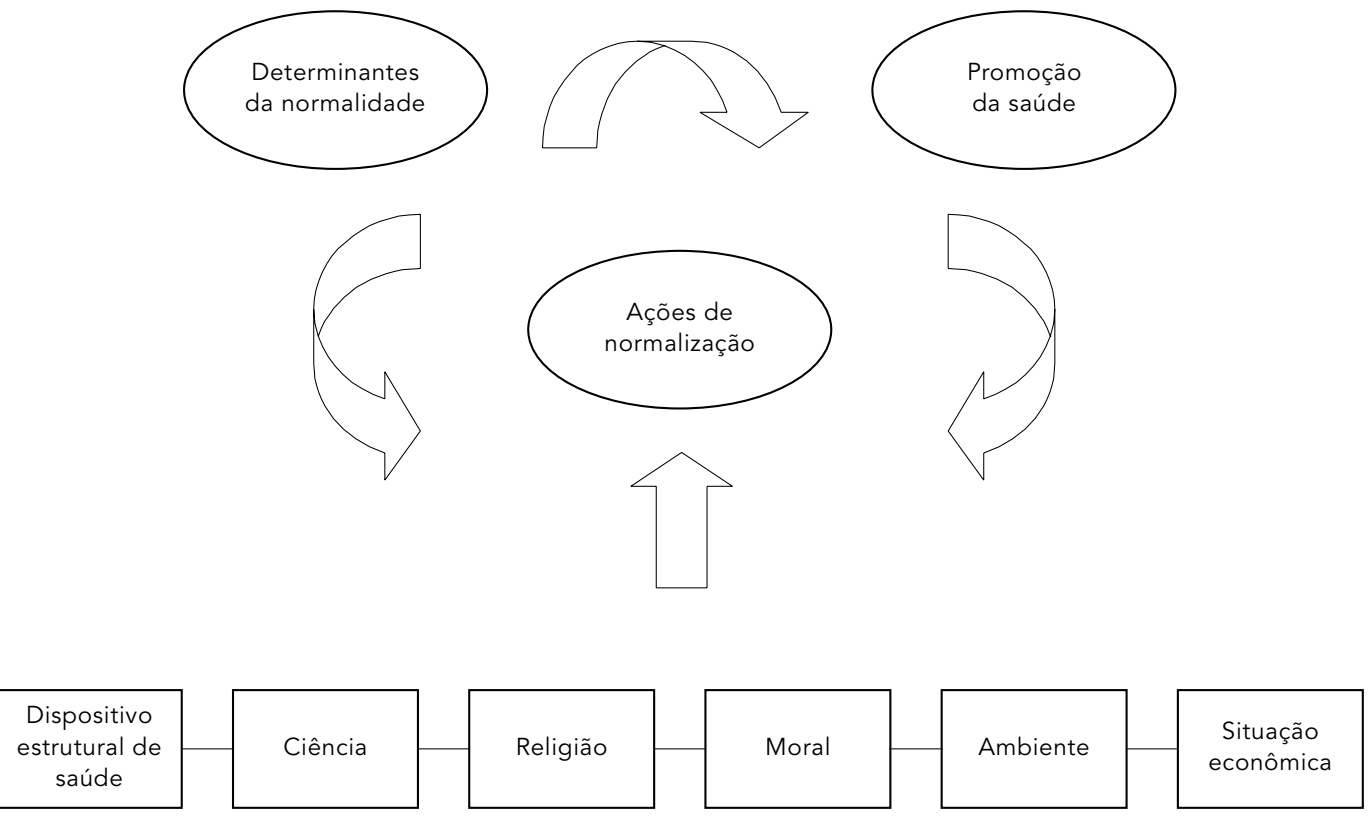
ximas de alguns discursos científicos, outras se mostraram ligadas ao modo de vida comum ou à singularidade de seus autores. A influência da biomedicina foi percebida quando os entrevistados admitiram que a normalidade compreende a saúde. Na linguagem local, estar normal tem o sentido de estar sadio. Estar sadio, por sua vez, é entendido tanto pelo prisma da saúde propriamente dita, quanto pela perspectiva da ausência de doença (Figura 4).

Assim, para alguns entrevistados, a existência de uma doença, por si só, não é considerada suficiente para situar o indivíduo dentro da anormalidade, de modo que a normalidade nem sempre corresponde à ausência de doença. No caso da epilepsia, por exemplo, embora ela seja considerada uma enfermidade, se o indivíduo volta a comportar-se do mesmo modo que antes da manifestação da crise, ele é tido como normal. A qualidade da reversibilidade, em última instância, constitui o fator determinante de tal categorização. Nessa perspectiva, a normalidade engloba tanto a saúde, quanto a presença e a ausência de doença.

Tal concepção é consoante com as proposições da epistemologia médica 33 e da psicanálise 51,52. De acordo com Canguilhem 33, a normalidade é uma categoria maior que engloba tanto a saúde quanto a doença como subcategorias. Para a psicanálise, ambos os fenômenos normais e patológicos são produzidos pelos mesmos mecanismos mentais 51. A intermediação cultural que produz a normalidade também pode ser fonte de adoecimento 52 .

Algumas idéias locais relacionadas à normalidade mental foram apresentadas apenas por um determinado indivíduo, como a ingestão excessiva de bebida alcoólica, a saída da cidade em que mora, a busca de um problema e a briga por qualquer motivo. Tais signos eram distintos e, alguns deles, até mesmo contrários aos signos de normalidade apresentados pelos demais entrevistados. De modo análogo à epistemologia de Canguilhem 33, a normalidade se apresenta, nessas situações, como uma questão individual. Tal percepção pode entrar em choque com a perspectiva científica em situações nas quais o fator considerado como normalizador seja visto como adoecedor pela ciência, como é o caso da ingestão excessiva de álcool: "tem uns dois meninos aqui que quando fica sem beber dá problema, e quando bebe fica normal".

\section{Considerações finais}

De acordo com o exposto, verificamos que, para os entrevistados, a normalidade e a saúde
Figura 4

Normalidade.

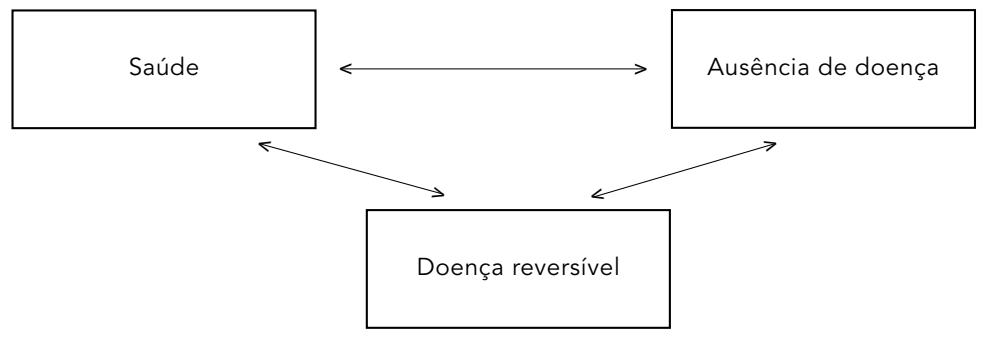

mental abrangem tanto a presença e a ausência de doença no plano biológico, quanto os costumes locais e a experiência subjetiva do bem-estar. Esses três diferentes aspectos correspondem, respectivamente, às dimensões primária, secundária e terciária da saúde 53 . A dimensão primária abrange as concepções de referência científica. A dimensão secundária diz respeito às concepções particulares ao grupo social pesquisado. A dimensão terciária está ligada às concepções próprias a um determinado indivíduo. A relação entre essas três dimensões e a saúde é análoga àquela entre as categorias inglesas "disease", "sickness", "illness" e a doença. "Disease" se refere ao mau funcionamento dos processos biológicos e ou psicológicos; “illness" diz respeito à experiência, percepção individual e reação à doença; e "sickness" se refere à dimensão social da doença 31,40 . Numa tentativa de traduzir essa tríade para a nossa língua, recentemente, Almeida Filho 23 e Almeida Filho et al. 39 propuseram a adoção da terminologia doença, patologia e enfermidade para os respectivos termos "sickness", "disease" e "illness". Nessa direção, defendemos que as categorias saúde, normalidade e bem-estar, ou seja, a saúde científica, social e privada são três dimensões do processo saúde-doença, tanto quanto o são patologia, doença e enfermidade. As práticas de saúde relacionadas ao setor profissional, como a biomedicina e a psicologia, encontram-se no eixo biopsicológico. No eixo social, estão as práticas terapêuticas não-profissionais, as ações de promoção de saúde realizadas pelos indivíduos na sua cotidianidade e as ações públicas de outros setores que não o de saúde, que repercutem no processo saúdedoença dos membros da comunidade. No eixo experiencial, localizam-se as ações singulares, propiciadoras da normalidade (Figura 5). 


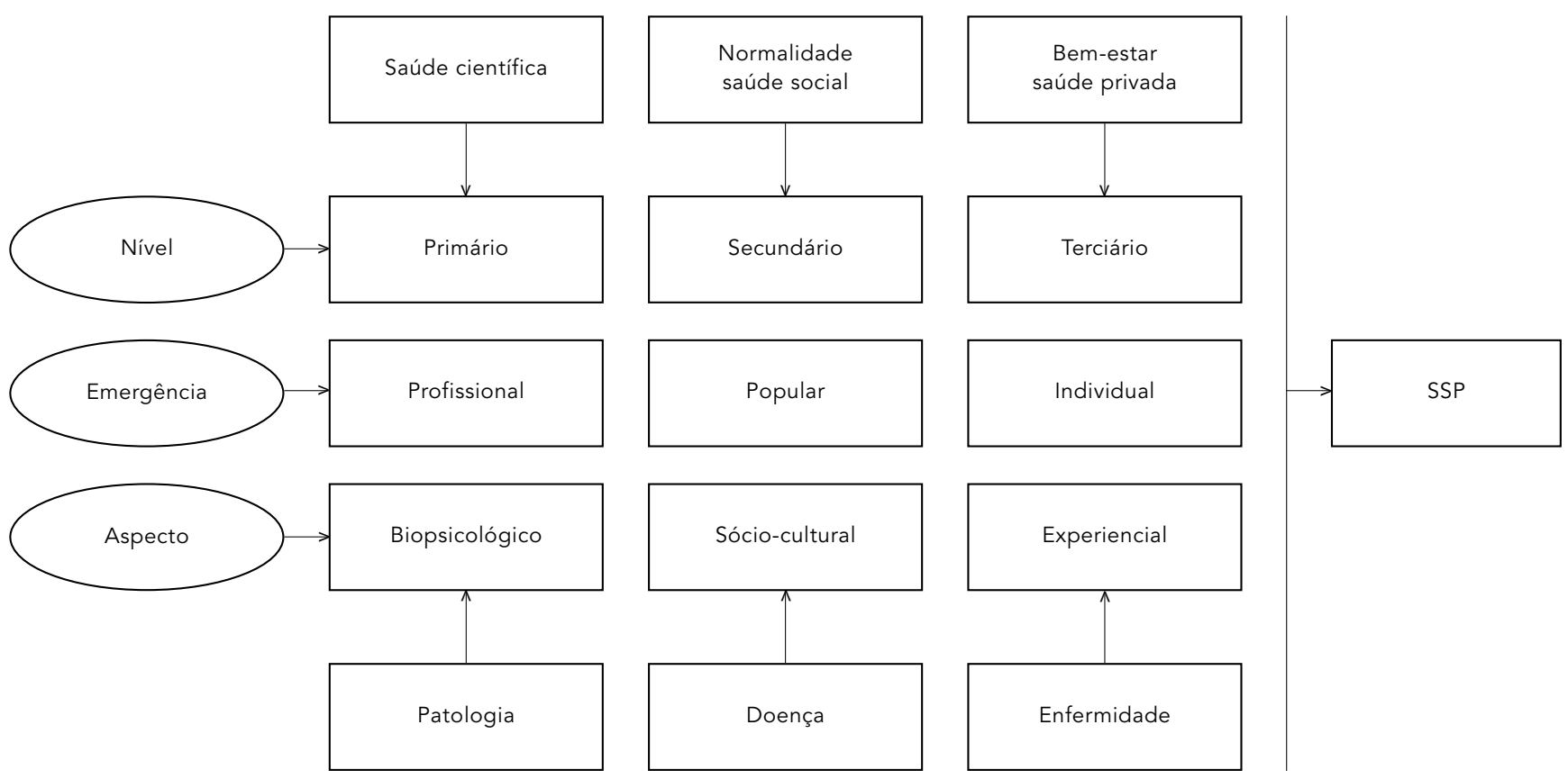

SSP = semiológicos, semânticos e pragmáticos

À medida que a normalidade e a saúde não se reduzem à ausência de doença e comportam aspectos biopsicossociais, não é suficiente que os sistemas de saúde estejam apenas centrados na cura das doenças sob o prisma biopsicológico. Torna-se necessário reestruturar as políticas de saúde, levando em consideração a dimensão cultural e subjetiva da normalidade em sua vertente positiva. Isso implica a contemplação das concepções populares e do bem-estar individual nas práticas de saúde.

Tal perspectiva tem repercussões sociais e éticas de longo alcance, uma vez que contempla o poder de outras camadas da população e a participação dos indivíduos nos processos de saúde-doença. Ou seja, não apenas os profissionais de saúde, mas também os terapeutas populares e os indivíduos possuem um saber que lhes possibilita atuar em outras dimensões do processo saúde-doença, de modo que maior se torna a autonomia dos indivíduos e a sua participação enquanto sujeitos ativos nos processos coletivos e individuais ligados à normalidade. Isso amplia o poder da população junto a outros setores da vida comunitária. Nesse sentido, a promoção da saúde se dá através de um processo dialógico, construído com os vários segmentos sociais. A eficácia das ações de saúde depende, portanto, de sua contextualização perante o universo sócio-econômico-político-cultural de cada grupo e o universo simbólico de cada indivíduo. Para que tal contextualização seja alcançada, reveste-se da maior importância a observação dos elementos semiológicos, semânticos e pragmáticos relacionados à normalidade mental, existentes em cada sociedade. 


\section{Resumo}

Este estudo investiga signos, significados e práticas relacionados à normalidade e saúde mental numa área do litoral norte da Bahia, Brasil. Discute concepções locais sobre a inexistência e existência exclusiva da normalidade mental, assim como os diversos pontos de vista sobre a normalidade mental total. Identifica protótipos de normalidade, como "pessoa normal", "quase normal" "e "falso normal", bem como signos que permitem reconhecer uma pessoa como mentalmente normal. Revela valores e conceitos que fundamentam a classificação local das pessoas quanto à normalidade mental e propõe um dispositivo estrutural de saúde composto por elementos morais, científicos, religiosos, ambientais e macrossociais. Analisa práticas locais de normalização e promoção de saúde mental e a configuração de um sistema de signos, significados e práticas de normalidade. Por fim, discute as dimensões primária, secundária e terciária da saúde. Analisa todos esses aspectos comparando as concepções locais com a literatura de referência científica sobre o tema, sobretudo a epistemologia médica, psicanálise, teoria sociológica do rótulo e antropologia médica.

Epistemologia; Psicanálise; Sociologia; Antropologia

\section{Colaboradores}

M. T. A. D. Coelho realizou a coleta complementar e análise dos dados, assim como a redação do artigo. N. Almeida Filho contribuiu na orientação e revisão deste trabalho.

\section{Referências}

1. Singh CBP. The hindu mental health: conceptual inquiry. Abhigyan 2001; 19:55-61.

2. Wang W, Miao X. Chinese students' concept of mental health. West J Nurs Res 2001; 23:255-68.

3. Bassett SF, Holt EA. New Zealand resident Tongan peoples' health and illness beliefs and utilisation of the health care system. Pac Health Dialog 2002; 9:40-7.

4. Esch T. Health in stress: change in the stress concept and its significance for prevention, health and life style. Gesundheitswesen 2002; 64:73-81.

5. Rask K, Astedt-Kurki P, Laippala P. Adolescent subjective well-being and realized values. J Adv Nurs 2002; 38:254-63.

6. Zhang J. Representations of health concepts: a cognitive perspective. J Biomed Inform 2002; 35:17-24.

7. Berger H. Health promotion - a new approach in psychiatry. Psychiatr Prax 2003; 30:14-20.

8. Maoz B, Rabin S. Salutogenesis - a story about the development of an idea. Harefuah 2003; 142: 550-3.

9. Natvig GK, Albrektsen G, Qvarnstrom U. Associations between psychosocial factors and happiness among school adolescents. Int J Nurs Pract 2003; 9:166-75.

10. Roose GA, John AM. A focus group investigation into young children's understanding of mental health and their views on appropriate services for their age group. Child Care Health Dev 2003; 29:545-50.

11. Rossen EK, Knafl KA. Older women's response to residential relocation: description of transition styles. Qual Health Res 2003; 13:20-36.

12. Salerno S, Marchetti E, Figà-Talamanca I. The concept of health in Italian occupational health legislation. Epidemiol Prev 2003; 27:244-6.

13. Waters E, Stewart-Brown S, Fitzpatrick R. Agreement between adolescent self-report and parent reports of health and well-being: results of an epidemiological study. Child Care Health Dev 2003; 29:501-9.

14. Wang W. Mainland Chinese students' concept of health. Asia Pac J Public Health 2004; 16:89-94.

15. Yip K-S. Taoism and Its impact on mental health of the chinese communities. Int J Soc Psychiatry 2004: 50:25-42.

16. Corin E, Uchôa E, Bibeau G, Harnois G. Les attitudes dans le champ de la santé mentale: repères théoriques et méthodologiques pour une étude ethnographique et comparative. Rapport Technique. Montreal: Centre de Recherche de l'Hôpital Douglas, Centre Collaborateur OMS; 1989.

17. Bibeau G. ¿iHay una enfermedad en las Américas? Otro camino de la antropología médica para nuestro tiempo. In: Pinzón C, Suárez PR, Garay G, editores. Cultura y salud en la construcción de las Américas. Bogotá: Instituto Colombiano de Antropología; 1993. p. 41-70.

18. Caroso C, Rodrigues N, Almeida Filho N, Corin E, Bibeau G. When healing is prevention: afro-Brazilian religious practices related to mental disorders and associated stigma in Bahia, Brazil. Curare Journal of Ethnomedicine 1997; 12:195-214.

19. Bibeau G, Corin E. Culturaliser l'épidémiologie psychiatrique. Les systèmes de signes, de sens et 
d'action en santé mentale. In: Charest P, Trudel F, Breton Y, editors. Marc-Adélard Tremblay ou la construction de l'anthropologie québécoise. Québec: Presses de l'Université Laval; 1994. p. 105-48.

20. Bibeau G. A step toward thick thinking: from webs of significance to connections across dimensions. Med Anthropol Q 1988; 2:402-16.

21. Corin E. Les détours de la raison. Repères sémiologiques pour une anthropologie de la folie. Anthropol Soc 1993; 17:5-20.

22. Bibeau G, Corin E. From submission to the text to interpretative violence. In: Bibeau G, Corin E, editors. Beyond textuality. Ascetism and violence in anthropological interpretation. Approaches to semiotics series. Berlin: Mouton de Gruyter; 1995. p. 3-54.

23. Almeida Filho N. For a general theory of health: preliminary epistemological and anthropological notes. Cad Saúde Pública 2001; 17:753-70.

24. Almeida Filho N. Modelos de determinação social das doenças crônicas não-transmissíveis. Ciênc Saúde Coletiva 2004; 9:865-84.

25. Freud S. Análise terminável e interminável. Rio de Janeiro: Imago; 1980.

26. Jaspers K. Psicopatologia geral: psicologia compreensiva, explicativa e fenomenologia. Rio de Janeiro: Atheneu; 1985.

27. Goffman E. Estigma: notas sobre a manipulação da identidade deteriorada. Rio de Janeiro: Zahar Editores; 1975.

28. Pondé M. Lazer e saúde mental: uma abordagem semântica e pragmática no campo da Saúde Coletiva [Tese de Doutorado]. Salvador: Instituto de Saúde Coletiva, Universidade Federal da Bahia; 2000.

29. Lima M. Pelo meu estado de viver triste: uma etnografia de comportamentos depressivos [Dissertação de Mestrado]. Salvador: Instituto de Saúde Coletiva, Universidade Federal da Bahia; 2000.

30. Peres MFT. O perigo na vida cotidiana: um estudo da relação entre doença mental e comportamento violento em uma comunidade litorânea da Bahia [Tese de Doutorado]. Salvador: Instituto de Saúde Coletiva, Universidade Federal da Bahia; 2001.

31. Young A. The anthropologies of illness and sickness. Annu Rev Anthropol 1982; 11:257-85.

32. Lakoff G. Women, fire and dangerous things. Chicago: The University of Chicago Press; 1987.

33. Canguilhem G. O normal e o patológico. Rio de Janeiro: Forense Universitária; 1978.

34. Gadamer H-G. The enigma of health. Palo Alto: Stanford University Press; 1996.

35. Good BJ. Medicine, racionality, and experience. An anthropological perspective. New York: Cambridge University Press; 1994.

36. Foucault M. Mental illness \& psychology. New York: Harper \& Row; 1976.

37. Canguilhem G. La connaissance de la vie. Paris: Vrin; 1965.

38. Good BJ, Good MJDV. The meaning of symptoms: a cultural hermeneutic model for clinical practice. In: Eisenberg L, Kleinman A, editors. The relevance of social science for medicine. Dordrecht: D. Reidel Publishing Company; 1980. p. 165-96.
39. Almeida Filho N, Coelho MTAD, Peres MFT. O conceito de saúde mental. Revista USP 1999; 43: 100-25.

40. Kleinman A. Patients and healers in the context of culture. Berkeley: University of California Press; 1980.

41. Kleinman A. Concepts and a model for the comparison of medical systems as cultural systems. In: Curie C, Stacey M, editors. Concepts of health, illness and disease: a comparative perspective. Oxford: Berg Publishers; 1993. p. 29-47.

42. Vasconcelos EM. A terapêutica médica e as práticas populares de saúde. Saúde Debate 1996; 49: 100-6.

43. Kleinman A. The illness narratives: suffering, healing \& the human condition. New York: Basic Books; 1988.

44. Paim JS, Almeida Filho N. A crise da saúde pública e a utopia da saúde coletiva. Salvador: Casa da Qualidade; 2000.

45. Westphal MF. O movimento Cidades/Municípios Saudáveis: um compromisso com a qualidade de vida. Ciênc Saúde Coletiva 2000; 5:39-51.

46. Teixeira CF, Paim JS. Planejamento e programação de ações intersetoriais para a promoção da saúde e da qualidade de vida. In: Teixeira CF, Paim JS, Vilasbôas AL, organizadores. Promoção e vigilância da saúde. Salvador: COOPTEC/Instituto de Saúde Coletiva; 2002. p. 59-78.

47. Nobre LCC. Trabalho de crianças e adolescentes: os desafios da intersetorialidade e o papel do Sistema Único de Saúde. Ciênc Saúde Coletiva 2003; 8:963-71.

48. De Negri Filho AAN. Adoção de uma estratégia promocional de qualidade de vida e saúde: transetorialidade das políticas públicas. In: Sperandio AMG, organizador. O processo de construção da Rede de Municípios Potencialmente Saudáveis. v. 2. Campinas: R. Vieira Gráfica e Editora; 2004. p. 15-55.

49. Sperandio AMG, Correa CRS, Serrano MM, Rangel HA. Caminho para a construção coletiva de ambientes saudáveis - São Paulo, Brasil. Ciênc Saúde Coletiva 2004; 9:643-54.

50. Moysés SJ, Moysés ST, Krempel MC. Avaliando o processo de construção de políticas públicas de promoção de saúde: a experiência de Curitiba. Ciênc Saúde Coletiva 2004; 9:627-41.

51. Freud S. Moisés e o monoteísmo. Três ensaios. Rio de Janeiro: Imago; 1980.

52. Lacan J. O seminário, livro 7: a ética da psicanálise. Rio de Janeiro: Jorge Zahar Editor; 1988.

53. Coelho MTAD, Almeida Filho N. Conceitos de saúde em discursos contemporâneos de referência científica. Hist Ciênc Saúde Manguinhos 2002; 9:315-33.

Recebido em 10/Nov/2004

Versão final reapresentada em 29/Mar/2005

Aprovado em 27/Abr/2005 